\title{
Quantity of Flowback and Produced Waters from Unconventional Oil and Gas Exploration
}

\author{
Andrew J. Kondash, Elizabeth Albright, and Avner Vengosh* \\ Nicholas School of the Environment, Duke University, Durham, NC 27708, USA.
}

*Corresponding author: Avner Vengosh (vengosh@duke.edu)

\section{Keywords:}

Hydraulic fracturing, wastewater, brines, unconventional energy, shale gas, tight oil, flowback fluids, produced water

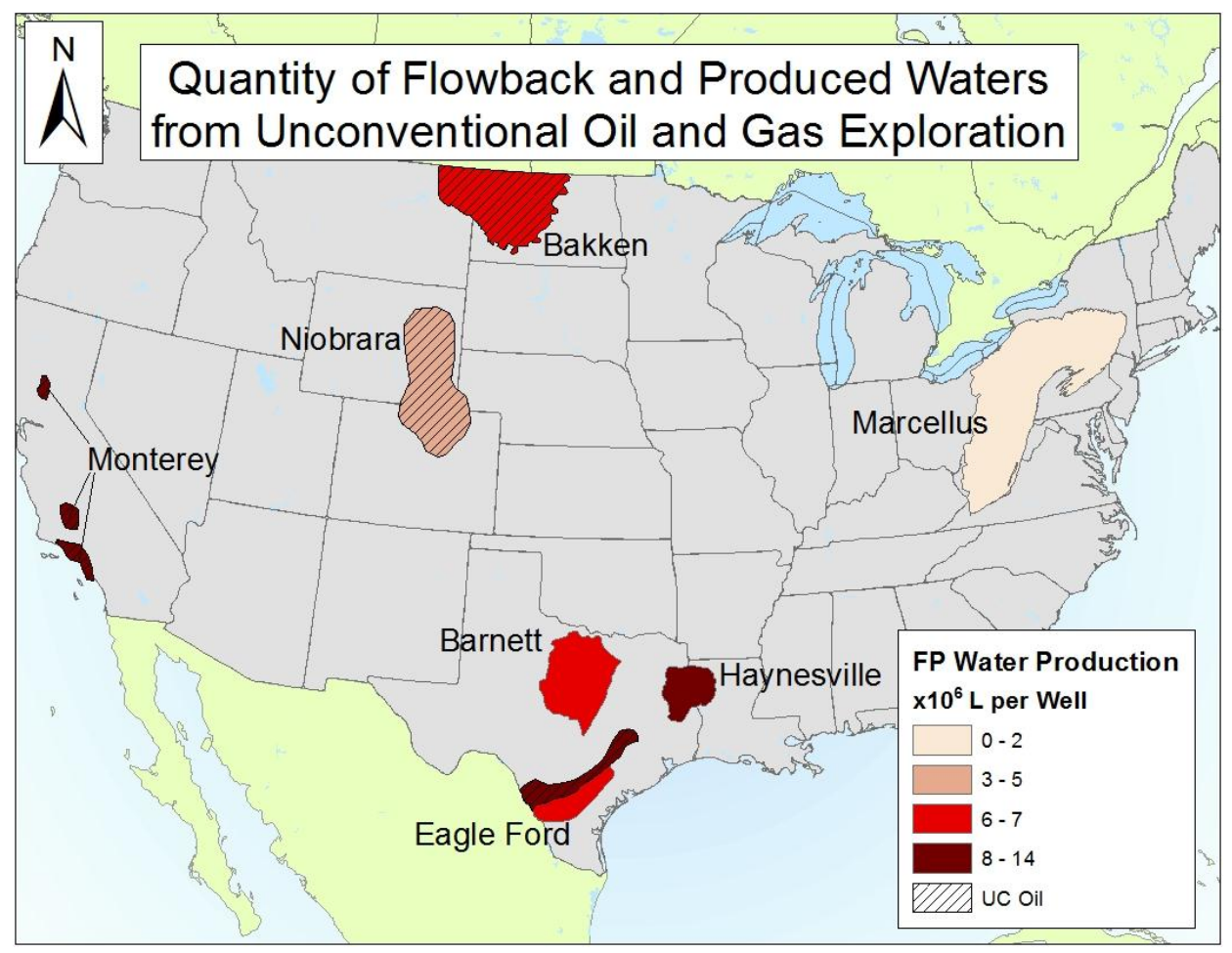

\section{Abstract}


The management and disposal of flowback and produced waters (FP water) is one of the greatest challenges associated with unconventional oil and gas development. The development and production of unconventional natural gas and oil is projected to increase in the coming years, and a better understanding of the volume and quality of FP water is crucial for the safe management of the associated wastewater. We analyzed production data using multiple statistical methods to estimate the total FP water generated from six of the major unconventional oil and gas formations in the United States. The estimated median volume ranges from 1.7 to 14.3 million liters ( 0.5 to 3.8 million gallons) of FP per well over the first 5-10 years of production. Using temporal volume production and water quality data, we show a rapid increase of the salinity associated with a decrease of FP production rates during the first months of unconventional oil and gas production. Based on mass-balance calculations, we estimate that only $4-8 \%$ of FP water is composed of returned hydraulic fracturing fluids, while the remaining 92-96\% of FP water is derived from naturally occurring formation brines that is extracted together with oil and gas. The salinity and chemical composition of the formation brines are therefore the main limiting factors for beneficial reuse of unconventional oil and gas wastewater.

\section{Introduction}

Following the rapid development of unconventional oil and gas in the United States, problems arising from the management, disposal, and spills of associated wastewater have become major environmental issues associated with hydraulic fracturing (Kahrilas et al., 2015; Lauer et al., 2016; McLaughlin et al., 2016; Mohan et al., 2013; Warner et al., 2013). Over the last decade, the most common disposal practice in the U.S. has involved injection of FP water into Class 2 brine disposal wells, which has recently been reported to induce micro-scale earthquakes (Clark and Veil, 2009; Ellsworth, 2013; Veil, 2015; Vengosh et al., 2014a; Weingarten et al., 2015), and in one case, also contamination of surface water (Akob et al., 2016; Kassotis et al., 2016). Geological limitations for injection wells, technological and economic barriers to treatment prior to disposal, water scarcity issues, and other management practices have led to an increased interest in evaluating the potential for reuse of FP water (Clark and Veil, 2009; Lutz et al., 2013; Stepan et al., 2010; Veil, 2010; Veil, 2015). Currently, well lifetimes are projected to be around 30 years, meaning that during downturn periods when only few new wells are being drilled, as is currently (summer and fall 2016) the case, thousands of wells already in 
production nation-wide will continue producing wastewater (Bai et al., 2013). Long term projections estimate that the growth of the hydraulic fracturing waste water treatment and recycling technologies will be significant, accounting for an estimated $\$ 3.8$ billion in revenue by 2025 (Wrobetz and Gartner, 2016). This projected growth calls for the necessity for a better understanding of the volumes and quality of wastewater produced from unconventional oil and gas exploration.

When a well is hydraulically fractured, it is done so in stages, with each stage being plugged, while the next is being drilled and fractured (Mohammad et al., 2014; Wang and Zhang, 2014). This creates an increase in pressure and a backup of both fluids and gas, while further stages are drilled. When the final stage is drilled, the fluids and gas are allowed to flow up out of the well for a period of time of up to about 2 months (Mantell, 2011). Many operators call this stage the "Flowback" period, where the water returning from the well is made up partially of drilling and the injected hydraulic fracturing fluids, and formation brines that are entrapped in the target formations and are extracted together with the oil and gas (Barbot et al., 2013; Gregory et al., 2011; Veil, 2010). Water generated after the flowback period, during the lifetime of oil and gas production, is commonly called "produced water" (Gregory et al., 2011; Mantell, 2011). The distinction between "flowback" and "produced water" definitions can be subjective when reporting data, and combined flowback and produced water (FP Water) data are reported in many instances without a specific distinction. In this study, we examine the volume and salinity of FP water generated through time, and use the water salinity data to distinguish the contribution of naturally occurring formation brines relative to the returned hydraulic fracturing fluids, which together generate the FP water (Bai et al., 2013; Blondes et al., 2015; Clark and Veil, 2009; Gregory et al., 2011; Mantell, 2011; Rowan et al., 2015; Veil, 2010; Veil, 2015; Veil et al., 2004; Warner et al., 2013). In many cases hydraulic fracturing is conducted with freshwater, although reuse of FP water is becoming more common in some areas like in the Marcellus Formation. When using freshwater for hydraulic fracturing, the FP water initially has low salinity, yet mixing with formation brines quickly raises the salinity of the water generated during the first several weeks of production and eventually leveling out to values that represent the maximum level of salinity of the formation brines, typically between 2 and 3 months since hydraulic fracturing (Balashov et al., 2015; Barbot et al., 2013). 
When quantifying the variations of water production volumes across formations with time, several methods have been used to generalize production rates within unconventional oil and gas basins in the U.S. (Bai et al., 2013; Balashov et al., 2015; Kondash and Vengosh, 2015; Lutz et al., 2013; Nicot and Scanlon, 2012; Nicot et al., 2014; Scanlon et al., 2014a; Scanlon et al., 2014b; Valko, 2009). Depending on the method used to interpret the data, vastly different quantities of wastewater have been reported for the same basin over similar time periods (Kondash and Vengosh, 2015; Scanlon et al., 2014a). In order to evaluate the reason for these discrepancies, we examine three different methods for quantifying FP water volume that include mean values, median values, and mean values obtain from DrillingInfo Desktop's Type Curve tool, a software that provides data on oil and gas wastewater volume (DrillingInfo, 2015). We show in this paper that the different methodologies could result in different volumetric estimates for FP water from unconventional oil and gas exploration.

Based on the integration of the wastewater volume and flowback water salinity data, this study aims to evaluate the overall and dynamic volume variations and differential salinity of wastewater generated from unconventional oil and gas wells. The ultimate objective of this study is to evaluate the relative proportions of returned hydraulic fracturing fluids relative to naturally occurring formation water in FP water during the lifetime of unconventional oil and gas wells. Through understanding the temporal variability in water quantity and water quality, researchers and industry professionals could evaluate, design, and implement best management practices for FP water (Murray, 2013; Stepan et al., 2010; Veil, 2015).

\section{Materials and Methods}

\subsection{Data Sources}

The DrillingInfo Desktop application was used to download data for wells in the major unconventional gas and oil formations in the United States, focusing on the oil, gas, and FP water production values of each well on a monthly basis (DrillingInfo, 2015). We used two methods to extract production values from DrillingInfo (DI) Desktop. The application's "Type Curve" function produces a decline curve for the reservoir of interest, compiling monthly production data and adjusting the curves as if each well began at the same time. This average monthly data was then downloaded and graphed to produce the first decline curve reported in this paper (light blue line in Figure S1, S2). DrillingInfo Desktop also allows the raw data to be 
downloaded for each well. We compiled monthly raw water, oil, and gas production data from the DI Desktop program, similarly adjusting first production to begin all wells at the same time, then created individual decline curves based on both the mean and median values obtained from the downloaded raw data. We calculated bootstrap confidence intervals of monthly production data for both the mean and median data sets (Figure S1, S2). The process of calculating bootstrap confidence intervals involves randomly sampling with replacement, from the original dataset to form a new distribution of sampled mean or median values (Efron et al., 1994; Lutz et al., 2013). This process is often called resampling. Bootstrap confidence intervals were calculated by resampling from the original dataset to form distributions of the resampled means and medians. Each resample was the same size as the original sampled data and the resampling process was repeated 10,000 times to form the resampled distributions. The $95 \%$ confidence intervals were gleaned from the resampled distributions (values at the 0.025 and 0.975 percentiles). The bootstrap confidence interval provides a reliable estimate of the variations of production at any point in time (shaded regions of Figure S1, S2, Table S1).

\subsection{Data Analysis}

Decline curves were first used by Arps (1945) to estimate ultimate recovery of currently producing conventional wells using limited data from initial production. Since then, varying empirical and theoretical methods have emerged attempting to estimate ultimate recovery of oil, natural gas, and FP water (Arps, 1945; Bai et al., 2013; Ilk et al., 2008; Jackson et al., 2014; Mutalik and Joshi, 1992; Valko and Lee, 2010; Wang and Zhang, 2014). We used data provided by DrillingInfo to generate decline curves for both oil and gas production from unconventional oil and gas wells (Figure S1), and similarly FP water generation (Figure S2). These decline curves were generated by aligning all historical production information to the same arbitrary starting time, month 1 , then taking the mean, median and a bootstrap confidence interval of each, using available data for each month of production. From this, the trend through time of production was examined, while cumulative production was developed using the integral of each decline curve from 0 to 10 years. Hydraulically fractured wells are projected to have lifespans of 30 or more years, however, our estimated ultimate recovery (EUR) was capped at 10 years because hydraulic fracturing has only been used on a widespread basis for the past 5-10 years. Additionally, we find that the amount and quality of long-term data ( $>10$ years) degrades with 
time (Figure S3), evidenced by widening bootstrap confidence intervals with time (Figure S2). Consequently, in order to maintain consistent precision of the dataset, we needed to trim the well production decline curves short of the 10 years goal in some cases. In all cases however, we assumed that the total volume present after the time period shown represents the full EUR, and note that the continued production may add only a relatively small volume to the total EUR.

Bootstrap confidence intervals have previously been used to estimate the variation of recovery of FP water (Lutz et al., 2013). Using the FP water generation, natural gas and oil production data, $95 \%$ bootstrap confidence intervals for both means and medians values were calculated for each month of production in each unconventional oil and gas formation. Using $\mathrm{R}$ software package, bootstrap resamples were drawn with replacement from each month's empirical distribution, using the same sample size as the original data. Mean and medians values were calculated for each resample. This process was repeated 10,000 times to form bootstrap distributions for the mean and median for each month in each formation. From the bootstrap distribution, the 0.025 and 0.975 percentile values were gleaned to form each of the confidence intervals. Comparisons of the bootstrap means and medians to the empirical values suggest very little bias in the confidence intervals.

\subsection{Wastewater Distinction}

Previous geochemical studies have shown that FP salinity increases during the first months of flow from shale gas and tight oil wells. Based on chemical and isotopic variations of the FP water, most studies have suggested the rise of the salinity reflects blending of typically low-saline injected hydraulic fracturing (HF) fluids and hypersaline formation brines (Balashov et al., 2015; Galusky and Hayes, 2011; Hayes, 2009; Rowan et al., 2015; Stepan et al., 2010; Warner et al., 2014). In most cases, initial FP production had low salinity (TDS), matching that of the injected fracturing fluid, but quickly increased in salinity with time (Figure 1).

We analyzed the variations of FP salinity from different time series that monitored the TDS variations in FP water following hydraulic fracturing. To distinguish the transition time from "flowback" water to "produced" water, we assume that FP is composed of a mixture between injected water (TDS zero in cases where fresh water is used, or higher TDS in cases where recycled FP water is used for hydraulic fracturing) and naturally occurring brine with TDS equal to the level measured at the endpoint of the dataset. We used dataset with long time series 
(> 3 months after HF) of flowback water monitoring from the Marcellus shale (Rowan et al. 2015; Hayes 2009; and new data from Duke University) and Barnett shale (Galusky and Hayes 2011). We calculated the relative fraction of the brine by using a mass-balance calculation between the injected water and the endpoint of each data string that represents the final TDS value (i.e., the brine). The TDS of FP was then used to calculate the relative fraction of the brine in the FP water blend (Figure 2). For cases where the injected water was from recycling water with TDS > 0, we used a mass-balance mixing equation between day 1 and final TDS. For example, Well A from Rowan et al. (2015) reported an initial TDS of 100,000 mg/L and a final TDS of $169,000 \mathrm{mg} / \mathrm{L}$ on day 438 after hydraulic fracturing, which we defined as "final TDS" because it was the final reported TDS value for that well. Using the following mass balance approach:

$$
\text { Percentage of Final TDS }=\frac{[T D S(x)-T D S(\text { day } 1)]}{[T D S(\text { final })-T D S(\text { day } 1)]}
$$

where TDS(x) represents the TDS of the flowback water at day $\mathrm{x}$ after hydraulic fracturing (Figure 1). In the case of well A reported by Rowan et al. (2015), Day 1 then had a value of 0\% brine contribution, while day 20, which reported a TDS of 140,000, had a value of 58\% of the natural occurring brine in the blend that consist the FP water. In our data analysis, we only included data strings containing 3 or more months' worth of data, assuming that the highest reported TDS for each data set represented close to $100 \%$ formation water (Figure S5). The 3month cutoff was selected because all of the long-term data series show a relative leveling off by this point (Figure 1, S5). We then used that line of best fit to calculate the relative mixing proportions of formation brines and returned hydraulic fracturing water (Figs 3 and S5). 


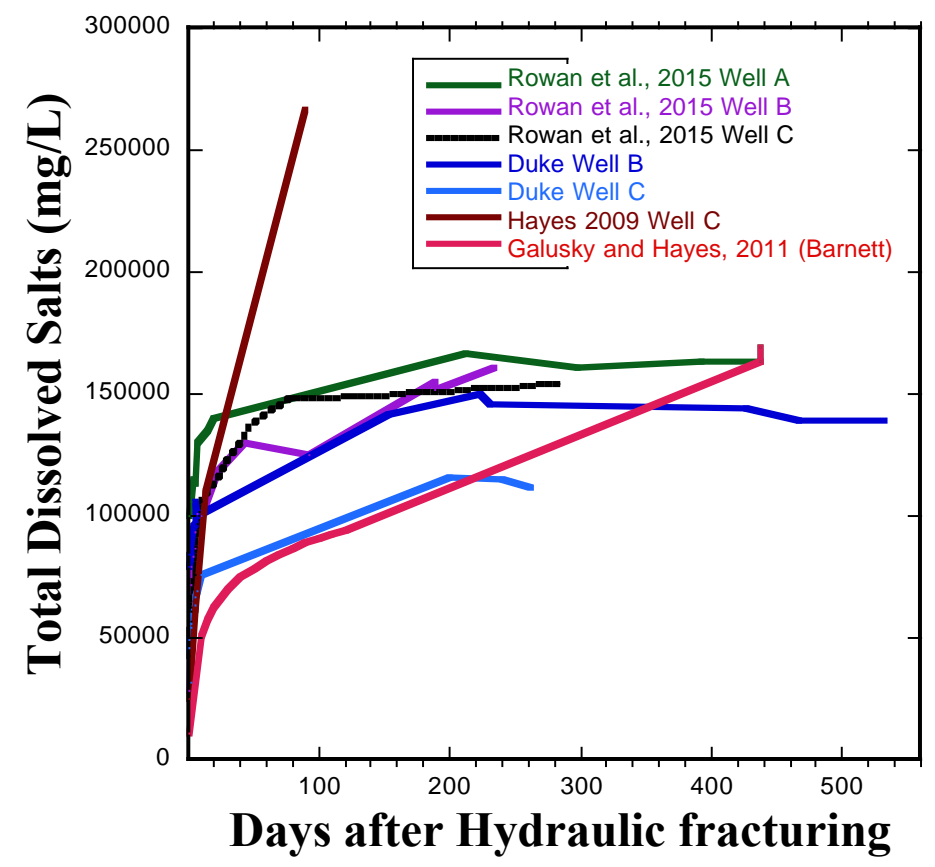

Fig. 1. Temporal increase in total dissolved salts (TDS) with time (days after hydraulic fracturing) in flowback and produced waters from individual oil and gas wells from the Marcellus shale (Hayes, 2009; Rowan et al., 2015; Duke University unpublished data) and Barnett shale (Galusky and Hayes, 2011). The data show a rapid rise of the salinity during the first 1-2 months days, followed by a period of leveling off. 


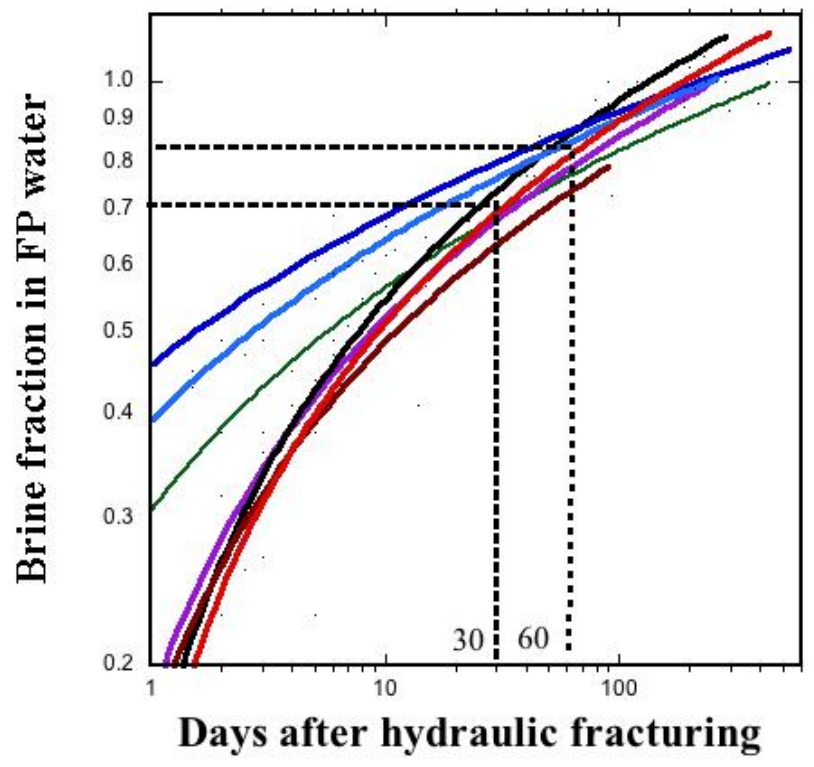

Fig. 2: Best fit curves of the calculated brine fraction in flowback waters with time (days after hydraulic fracturing; log scale), from individual wells with long TDS monitoring record (>3 months) from the Marcellus and Barnett shales (see line symbols in Fig. 1). The rapid increase of TDS with time following hydraulic fracturing infers a high contribution of the naturally occurring brine component in the blend, with a mean of $~ 70 \%$ after 30 days and $85 \%$ after 60 days following hydraulic fracturing. 


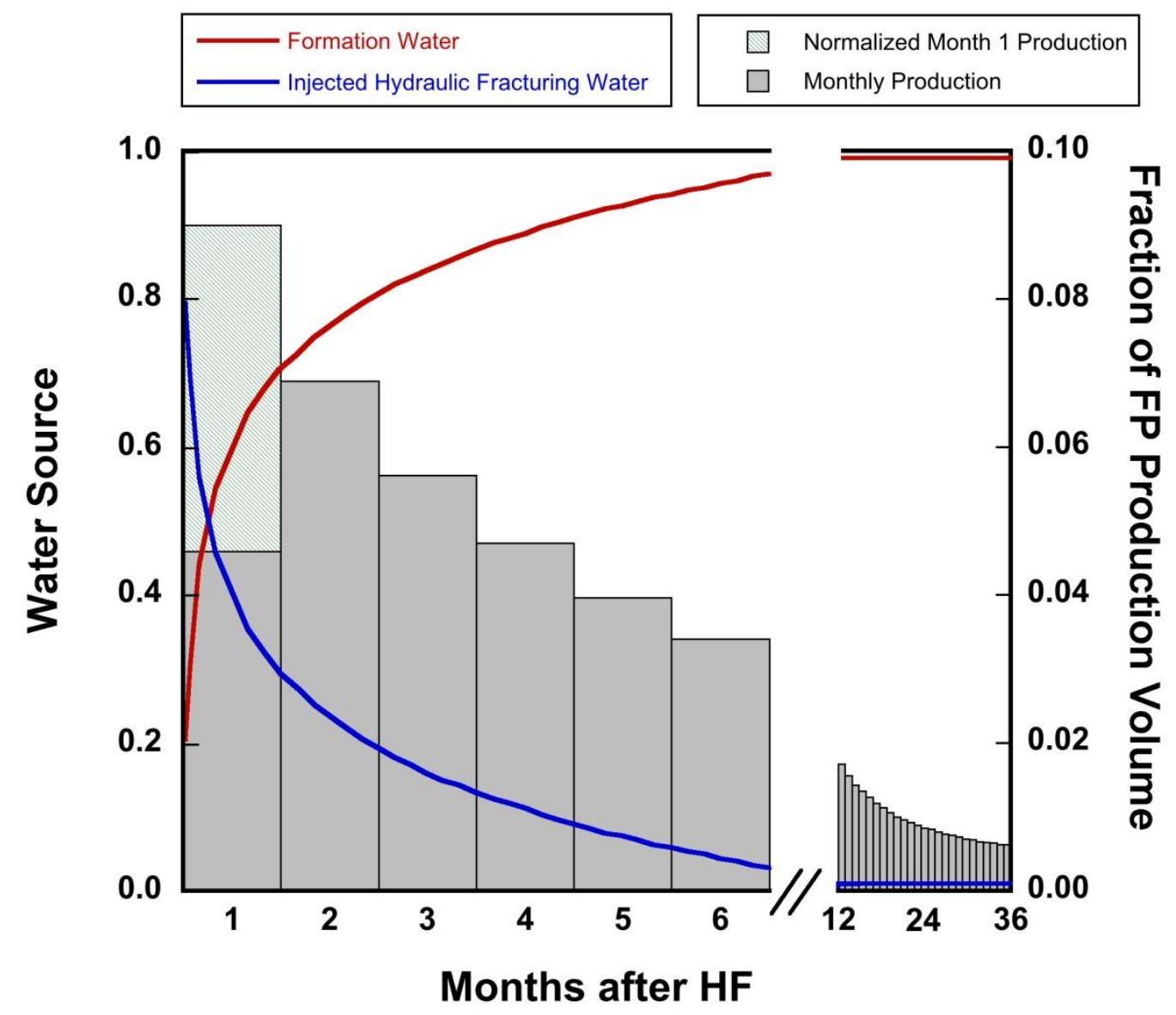

Figure 3. Temporal variations of the fractions of the two water sources that compose the FP water (left Y-axis) and the fraction of FP production volume relative to the overall FP water volume production (right y-axis), following hydraulic fracturing (HF). The two water sources include the retuned hydraulic fracturing water and the shale formation brine that together compose the FP water. Fraction data of the water source was synthesized from integrated FP water time series datasets (see also Figure 2 and Figure S5). The mixing relationships were based on TDS mass-balance calculations between the injected water with low TDS and formation brine with high TDS, represented by FP waters collected at later stages after hydraulic fracturing (data combined from Figure 1, $\mathrm{R}^{2}=0.84, \mathrm{n}=132$ time points; see Figure S5). We show normalized month 1 production because well production data is available by calendar month, it is likely that for many wells, month 1 production is not representative of a full month of production (see Table S3 and Figure S7). 


\section{Results}

\subsection{Water Quantity Analysis}

Our data show that the total FP production (median) volumes in the major unconventional basins in the U.S. ranged from 1.72 to 14.32 million liters ( 0.45 to 3.78 million gallons) per well (Table 1). The data show that FP production is commonly associated with unconventional oil and shale gas production rates (Gregory et al., 2011; Veil et al., 2004) and is characterized by high flow rates in the first few months, followed by a slow leveling off of production in subsequent months to years (Figure S2). In most cases, production values calculated from the median values were substantially lower than both the mean values and the DrillingInfo type curve methods. This is most likely a result of upper skewed nature of the empirical distributions of the datasets (Figure S4), combined with larger outliers disproportionally affecting the mean values and the values extracted from the DrillingInfo type curve method. We observe large bootstrap confidence intervals for the mean of Eagle Ford Oil data, while in many of the other basins, we see an increase in the spread of data through time along with fewer data points (Figure S3). Examining the temporal nature of production, we see that between $10 \%$ and $20 \%$ of the total FP production of a well over its lifetime (restricted to 10 years) occurs during the first three months, while an estimated 20-50\% of total FP production volume occurs within the first 6 months (Table 2). 
Total FP Water

\begin{tabular}{|l|c|c|c|}
\hline \multicolumn{1}{|c|}{ Basin } & Median Water & Mean Water & DI Water \\
\hline Bakken & 6.82 & 22.87 & 30.53 \\
Barnett & 9.01 & 28.99 & 73.91 \\
\hline Eagle Ford Gas & 6.09 & 20.06 & 20.49 \\
Eagle Ford Oil & 12.28 & 67.73 & 23.66 \\
Haynesville & 11.55 & 17.70 & 18.13 \\
Marcellus* & 1.72 & 3.94 & NA \\
Monterey** & 14.32 & 28.34 & NA \\
Niobrara & 5.70 & 18.45 & 6.09 \\
\hline
\end{tabular}

Total Oil (grey) and Gas (white) Production

\begin{tabular}{|l|c|c|c|c|}
\hline \multicolumn{1}{|c|}{ Basin } & Production Type & Median OG & Mean OG & DI OG \\
\hline Bakken & Oil & 0.16 & 0.21 & 0.24 \\
Barnett & Gas & 1.06 & 1.26 & 1.43 \\
\hline Eagle Ford Gas & Gas & 1.26 & 1.53 & 1.54 \\
Eagle Ford Oil & Oil & 0.20 & 0.61 & 0.24 \\
Haynesville & Gas & 3.25 & 3.74 & 4.10 \\
Marcellus & Gas & 2.76 & 3.45 & 3.92 \\
Monterey** & Oil & 0.02 & 0.02 & \\
Niobrara & Oil & 0.09 & 0.11 & 0.10 \\
\hline
\end{tabular}

Table 1. Estimated FP water production (million liters per well) on left, and Oil (shaded gray; million Bbl per well) and Gas (white; million MCF per well) productions on right. The data is based the median ("Median Water", "Median OG"), mean ("Mean water", "Mean OG"), and DrillingInfo decline curve methods ("DI water", "DI OG"). Data from oil producing formations are marked with shaded grey, while gas producing formations are white. Data for FP production from the Marcellus formation (*), along with FP production and oil production from the Monterey formation in California $(* *)$ were not available on DrillingInfo and were downloaded from state government websites (CADOC; PADEP, 2015).

First 3 Months
\begin{tabular}{|l|c|c|c|}
\hline \multicolumn{1}{|c|}{ Basin } & Median Water & Mean Water & DI Water \\
\hline Bakken & 0.82 & 1.55 & 3.61 \\
Barnett & 0.94 & 2.79 & 9.16 \\
\hline Eagle Ford Gas & 1.50 & 4.20 & 4.09 \\
Eagle Ford Oil & 2.53 & 5.98 & 3.80 \\
Haynesville & 2.19 & 3.44 & 3.16 \\
Niobrara & 0.91 & 2.83 & 1.37 \\
\hline
\end{tabular}

First 3 Months \% of Total Production

\begin{tabular}{|l|c|c|c|}
\hline \multicolumn{1}{|c|}{ Basin } & Median Water & Mean Water & DI Water \\
\hline Bakken & $12 \%$ & $7 \%$ & $12 \%$ \\
\hline Barnett & $10 \%$ & $10 \%$ & $12 \%$ \\
Eagle Ford Gas & $25 \%$ & $21 \%$ & $20 \%$ \\
Eagle Ford Oil & $21 \%$ & $9 \%$ & $16 \%$ \\
Haynesville & $19 \%$ & $19 \%$ & $17 \%$ \\
Niobrara & $16 \%$ & $15 \%$ & $22 \%$ \\
\hline
\end{tabular}

\begin{tabular}{|l|c|c|c|}
\multicolumn{1}{|c|}{ First 6 Months } & FP Production (Million Liters) \\
\hline \multicolumn{1}{|c|}{ Basin } & Median Water & Mean Water & DI Water \\
\hline Bakken & 1.29 & 2.56 & 5.87 \\
Barnett & 1.71 & 5.01 & 16.09 \\
Eagle Ford Gas & 2.93 & 8.40 & 8.11 \\
Eagle Ford Oil & 4.55 & 10.29 & 6.45 \\
Haynesville & 3.51 & 5.80 & 5.57 \\
Niobrara & 1.22 & 3.78 & 1.83 \\
\hline
\end{tabular}

First 6 Months
\begin{tabular}{|l|c|c|c|}
\hline \multicolumn{1}{|c|}{ Basin } & Median Water & Mean Water & DI Water \\
\hline Bakken & $19 \%$ & $11 \%$ & $19 \%$ \\
Barnett & $19 \%$ & $17 \%$ & $22 \%$ \\
\hline Eagle Ford Gas & $48 \%$ & $42 \%$ & $40 \%$ \\
Eagle Ford Oil & $37 \%$ & $15 \%$ & $27 \%$ \\
Haynesville & $30 \%$ & $33 \%$ & $31 \%$ \\
Niobrara & $21 \%$ & $21 \%$ & $30 \%$ \\
\hline
\end{tabular}

Table 2. Water production volume (million Liters) and percent of the first 3 months (left) and 6 months (right) of oil and gas wells operation from different unconventional basins. In each case, only $10-25 \%$ of total FP water is generated during the first 3 months of well operation, while an estimated 20-50\% of FP water is generated during the first 6 months of operation. Shaded and white cells refer to unconventional oil and shale gas producing formations, respectively.

\subsection{Salinity Analysis}

The salinity of the FP water rapidly increases through time following hydraulic fracturing (Fig. 1). Previous studies have shown that the changes in the salinity chemistry during the first few days to weeks reflect mixing between the returned injected water and hypersaline formation brine (Galusky and Hayes, 2011; Hayes, 2009; Rowan et al., 2015; Warner et al., 2014). Based 
on this geochemical criterion, we calculated the relative brine component in FP water for individual wells with long ( $>3$ months) monitoring data. The data show that the average brine faction values for the 7 case studies are $0.71 \pm 0.05$ and $0.81 \pm 0.05$ for FP water after 30 days and 60 days, respectively (Fig. 2). Consequently, the brine constitute $\sim 70 \%$ of the FP water after a month and $\sim 80 \%$ after two months from initial hydraulic fracturing. Our analysis shows that the rise of the salinity, and thus the contribution of the formation brine to the FP blend, is far more rapid than the decline of the production rate (Figure 3). Consequently, during the high peak of FP production, the FP water is predominantly composed of the formation brine.

Previous studies have shown that the absolute volume of the flowback water is much lower than the volume of the injected water (Hayes, 2009). Yet the results shown in this study suggest that the FP water is mainly composed of the formation brine and thus the relative volume of the injected water that is returned to the surface is even lower than previously estimated. These results reinforce previous scenario that suggested that the majority of the injected hydraulic fracturing and drilling fluids have been sequestered into the shale formations through imbibition after about 3 months, and in many cases even sooner (Birdsell et al., 2016). Based on mass-balance calculations, we find that during the lifetime of a well a maximum of $8 \%$ of the total FP water is composed of returned hydraulic fracturing fluids (Table 3). When compared to the production volumes and amount of water used for hydraulic fracturing (Gallegos et al., 2015; Kondash and Vengosh, 2015; Table S2 and S3) it is clear that most of the injected water is retained in the shale or tight sand formations, and the return flow is mainly composed of naturally occurring formation brine. 


\begin{tabular}{|c|c|c|c|c|c|}
\hline Basin & $\begin{array}{c}\text { Volume } \\
\text { Injected Fluids }\end{array}$ & $\begin{array}{c}\text { Total FP } \\
\text { Water }\end{array}$ & $\begin{array}{c}\text { Cumulative Injected } \\
\text { Water Returning }\end{array}$ & $\begin{array}{c}\text { Fraction of Injected } \\
\text { Fluids Returning }\end{array}$ & $\begin{array}{c}\text { Fraction of Total FP } \\
\text { Water }\end{array}$ \\
\hline Bakken & 7.49 & 6.82 & 0.27 & $4 \%$ & $4 \%$ \\
Barnett & 14.42 & 9.01 & 0.29 & $2 \%$ & $3 \%$ \\
\hline Eagle Ford Gas & 13.70 & 6.09 & 0.46 & $3 \%$ & $8 \%$ \\
Eagle Ford Oil & 15.06 & 12.28 & 0.77 & $5 \%$ & $6 \%$ \\
Haynesville & 19.45 & 11.55 & 0.69 & $4 \%$ & $6 \%$ \\
Niobrara & 1.32 & 5.70 & 0.29 & $22 \%$ & $5 \%$ \\
\hline
\end{tabular}

Table 3. Volume of injected HF water $\left(x 10^{6} \mathrm{~L}\right)$, Total FP water $\left(\times 10^{6} \mathrm{~L}\right)$, estimated Cumulative Injected HF water $\left(x 10^{6} \mathrm{~L}\right)$ returned to the surface (based on the salinity mass-balance), Percent of the volume of the returned injected water compared to the volume of water used for hydraulic fracturing in the different basins (data from Kondash and Vengosh, 2015), and Percent of the total volume of FP water made up of returned HF water. Cumulative injected water was calculated by multiplying the production from each month (Figure S2) by the percentage of injected water (Figure 3, S5) at the midpoint of each month of oil and gas wells production.

\section{Discussion}

There are a number of ways to analyze and quantify production data on a basin-wide scale (Arps, 1945; Bai et al., 2013; Ilk et al., 2008; Jackson et al., 2014; Kondash and Vengosh, 2015; Lutz et al., 2013; Mutalik and Joshi, 1992; Nicot et al., 2014; Valko, 2009; Valko and Lee, 2010; Wang and Zhang, 2014). Several studies have shown estimated ultimate recovery of oil, natural gas, and FP water values similar to the results generated in this study, mostly agreeing with the reported median FP production values (Nicot and Scanlon, 2012; Nicot et al., 2014; Scanlon et al., 2014a). Our data show that the production rate and salinity of FP water vary significantly during the lifetime of an unconventional oil and gas well, with high rates and relatively lower salinity during the first phase (up to 2-3 months) relative to significant (order of magnitude) lower production rates and typically much higher salinity during the rest of a well lifetime (> 6 months) (Figs. 3 and S2). These dynamics require differential management modes during oil and gas operations; management of relatively large volume of FP water during the early stages of unconventional oil and gas well operation and transport to offsite water treatment plants for reuse or injection into class II underground injection wells. In contrast, operation during most of a well lifetime (i.e., > 6 months) involves a much lower volume. Because the return of most injected hydraulic fracturing fluids is restricted to the first few months after initial hydraulic fracturing, the wastewater that will be generated during that time could contain some of the injected hydraulic fracturing additive chemicals, since the FP water is a blend of returned 
injected fluids and formation brine. We expect that the risks associated with man-made chemicals found in hydraulic fracturing fluids would be negligible after the first several months of operation, since the FP water at that stage of evolution is composed of mostly naturally occurring formation brine. Consequently, many of the risks associated with hazardous chemicals in hydraulic fracturing fluids are restricted to $4-8 \%$ of the total FP wastewater volume. Nonetheless, we argue that the major concern with long-term FP water production rests with the hazards associated with the naturally occurring constituents of the formation brines, among which are halides, heavy metals, metalloids, naturally occurring radioactive materials (NORM), and other contaminants such as ammonium and iodide (Barbot et al., 2013; Harkness et al., 2015; Kondash et al., 2014; Lauer et al., 2016; Orem et al., 2014; Thacker et al., 2015; Thurman et al., 2014; Vengosh et al., 2014b; Warner et al., 2013).

Prediction of the wastewater volume that is expected to come from unconventional oil and gas operations is an important factor for sustainable operations. While many studies have attempted to predict oil and gas production using both empirical and theoretical models (Arps, 1945; Ilk et al., 2008; Valko, 2009; Valko and Lee, 2010), few have used these methods to predict wastewater production (Bai et al., 2013; Kondash and Vengosh, 2015; Yu et al., 2016). Here we present baseline values within different formations, where FP water production assessments are provided. Because of the right skewed distribution of the data (Figure S4) reported in this study, we suggest that using mean production values may overestimate FP production. Instead, we posit that using bootstrapped median confidence intervals is the most appropriate approach to generalizing production, and thus caution future studies to take the distribution of the data into account when creating models for projected wastewater production rates.

Several studies have identified and defined different contaminants commonly found in injected hydraulic fracturing fluids based on the chemicals toxicity (Hurley et al., 2016; Kahrilas et al., 2015; McLaughlin et al., 2016; Mohan et al., 2013; Yost et al., 2016a; Yost et al., 2016b). With a better understanding of the hazards associated with hydraulic fracturing fluids, it is possible to use our estimates of the percentage of brine in flowback water (Figure 3) in order to predict the concentration of contaminants of interest in water, which could be used to assess the environmental impact of spilled water, or alternatively, to adjust targeted treatment processes on recovered water. 
Due to the relatively large volume of FP water that is generated during the first few months, there might be some incentive to capture that FP water for reuse, as in some cases it will only require a relatively lower degree of treatment and dilution before being able to be utilized again as hydraulic fracturing fluid (Figure 4). However, saline formation waters that compose 92-96\% of FP water are characterized by higher salts, metals, and NORM, which require much more intensive treatment or dilution to become useable for beneficial reuse. Alternatively, recent studies have suggested that new HF technologies can utilize hypersaline brines with TDS up to $90,000 \mathrm{mg} / \mathrm{L}$, depending on the scale potential and ions present such as calcium, sulfate, and magnesium, allowing for minimal pretreatment before it is reused for HF (Elsarawy et al., 2016; Hayes, 2009)

Based on the large variations in the salinity of formation water in the U.S. (Fig. 4), we can distinguish between formations associated with high (TDS> 200,000 mg/L; such as the Marcellus and Bakken formation), medium (50,000 to 100,000; Haynesville, Barnett), and lower ( $<50,000 \mathrm{mg} / \mathrm{L}$; Niobrara, California, Eagle Ford) salinity brines. We use seawater salinity (TDS 35,000 mg/L) as a useable threshold for economic treatment. Our data show the rise of the salinity of the flowback water during the first few months results in different salinity ranges for the different basins; from high proportions of manageable water with relatively low salinity (Niobrara basin) to hypersaline brines (Bakken, Marcellus; Fig. 4).

Based on these variations, we estimate that the western basins (Niobrara, California, Eagle Ford) with relatively low salinity in the formation brines have more potential for reuse for hydraulic fracturing and/or other beneficial use. Based on the relationships between the median EUR values reported for oil (Eagle Ford, California, Niobrara) and gas (Eagle Ford), and median FP water values (Table 1), we estimate that the FP intensity (i.e., FP water volume per energy unit) for the low saline FP in these basins is approximately $60 \mathrm{~L} / \mathrm{bbl}$ and 5L/MCF for tight oil and shale gas, respectively. Consequently, we estimate that since the beginning of the unconventional oil and gas operations, a total volume of 22,000, 10,000, and 120,000 million liters have been generated in Niobrara, California, and Eagle Ford basins, respectively. Future research should examine the potential of utilizing the relatively low saline FP water from these basins for other beneficial uses such as irrigation and the role and possible limiting factors of other chemical constituents of the FP waters in these basins. 


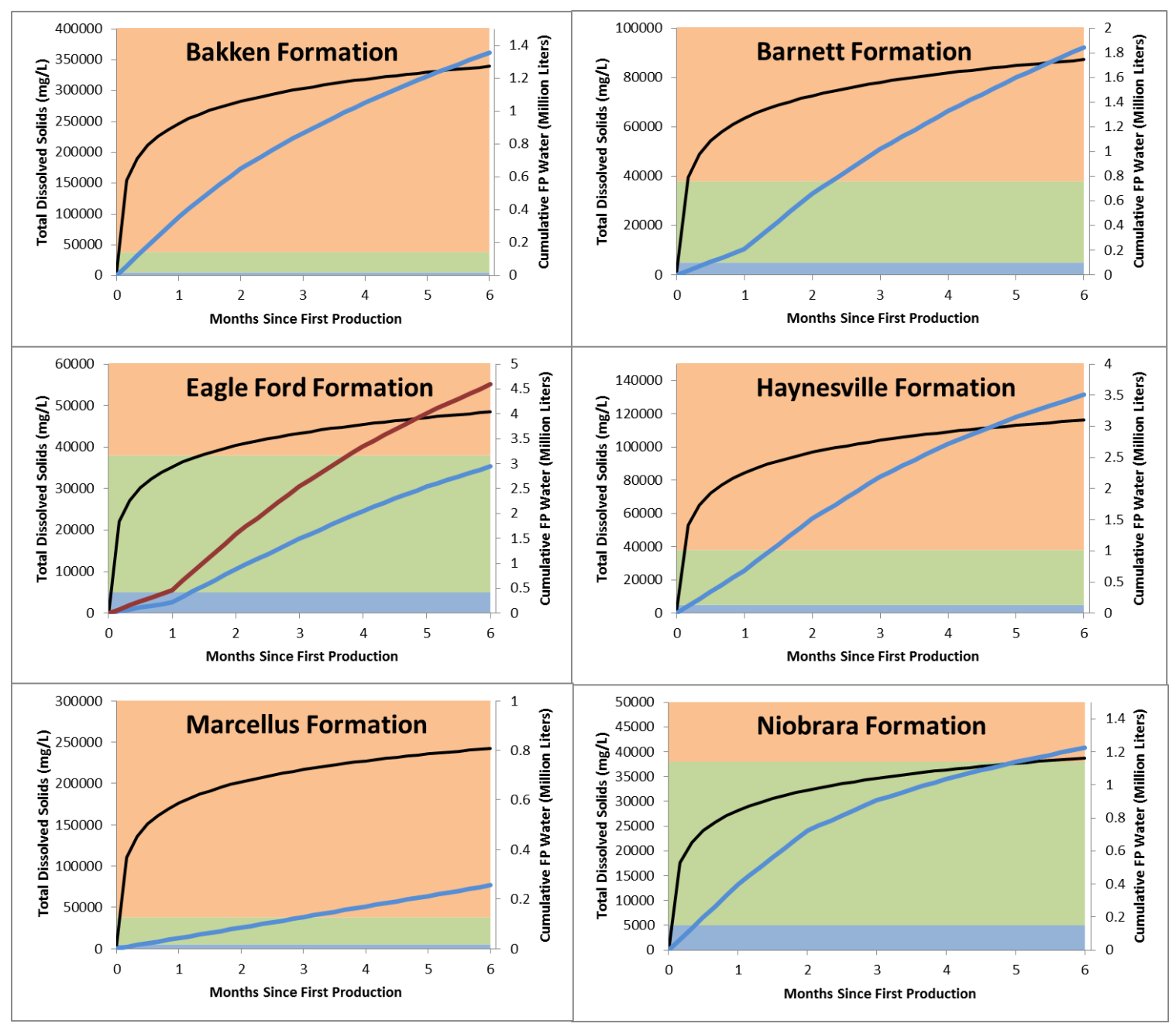

Figure 4. Salinity (black line) and cumulative water production (blue line) through the first 6 months of oil and gas production interpolated using percentage values obtained from Figure 3 multiplied by the final production TDS shown in Figure S6 and Table S3. The red line on the Eagle Ford graph shows water for oil while the blue shows water for gas. The shaded regions represent a classification of water as brackish (blue $\sim 5,000 \mathrm{mg} / \mathrm{L} \mathrm{TDS}$ ) saline (green 5,00033,000 mg/L TDS), and hypersaline brine (orange >33,000 mg/L TDS).

\section{Conclusions}

By examining the results from different statistical methods of decline curve development of FP water from unconventional oil and gas operations (Figure S1, S2) we show a pattern that begins with high production rates during the first few months of production, followed by an order of magnitude reduction and flattening out of production rates over the course of production. This is consistent with observations made in previous studies (Mutalik and Joshi, 1992; Nicot et al., 2014; Wang and Zhang, 2014). In many cases, over 50\% of the FP water is generated within the first year of an unconventional well, with a majority of that FP water 
composed of hypersaline formation water (Figs 3 and 4). Due to the large differences seen in the estimated per well production using different data-generalization methods, we suggest that the selected method used to generalize FP production data and determine an EUR rate may have a significant impact on the estimated value of the volume of FP water during the lifetime operation of an unconventional oil and gas well (Table 1). Our analysis demonstrates that using bootstrapped median approach is the most valid method with lower uncertainty relative to the other statistical methods that suffer from large variations and skewed data towards higher values.

While the initial production volumes in each formation are significant, they only represent a small fraction of the volume of the water injected for hydraulic fracturing (Table S2) as well as a small fraction (10-25\%) of total FP production (Table 2). Additionally, we show that it is possible to differentiate between the contribution of returned injected hydraulic fracturing fluids and naturally occurring formation brines water using the combined salinity and geochemistry of the FP water. We show that the ratio of injected fluids to formation water is consistently low among different unconventional oil and gas formations. Finally, we estimate that about 4-8\% of total FP water is made up of the retuned injection fluids with potentially toxic hydraulic fracturing chemicals, while the majority (92-96\%) of wastewater generated from unconventional oil and gas wells is composed of naturally occurring formation brines, which contain other chemicals with potential environmental and human health risks and required advanced treatment technologies for remediation and/or beneficial use.

\section{Acknowledgments}

We gratefully acknowledge funding from the National Science Foundation (EAR1441497) and Duke University Energy Initiative grant. AK was also supported by the National Science Foundation PIRE grant (OISE-12-43433). We thank three anonymous reviewers and the editor for a prompt and insightful review process that contributed and improved the quality of the earlier version of this paper.

\section{References}

Akob, D. M., A. C. Mumford, W. Orem, M. A. Engle, J. G. Klinges, D. B. Kent, and I. M. Cozzarelli 2016. Wastewater Disposal from Unconventional Oil and Gas Development Degrades Stream Quality at a West Virginia Injection Facility, Environ. Sci. Technol., Article ASAP.

Arps, J. J. 1945. Analysis of Decline Curves, Transactions of the American Institute of Mining and Metallurgical Engineers, 160, 228-247.

Bai, B., S. Goodwin, and K. Carlson 2013. Modeling of frac flowback and produced water volume from Wattenberg oil and gas field, J. Pet. Sci. Technol., 108, 383-392. 
Balashov, V. N., T. Engelder, X. Gu, M. S. Fantle, and S. L. Brantley 2015. A model describing flowback chemistry changes with time after Marcellus Shale hydraulic fracturing, AAPG Bull., 99(1), 143-154.

Barbot, E., N. S. Vidic, K. B. Gregory, and R. D. Vidic 2013. Spatial and Temporal Correlation of Water Quality Parameters of Produced Waters from Devonian-Age Shale following Hydraulic Fracturing, Environ. Sci. Technol., 47(6), 2562-2569.

Birdsell, D. T., H. Rajaram, and G. Lackey 2016. Imbibition of hydraulic fracturing fluids inot partially saturated shale, Water Resour. Res., 51, 6787-6796.

Blondes, M. S., K. D. Gans, J. J. Thordsen, M. E. Reidy, B. Thomas, Y. K. Kharaka, and E. L. Rowan, 2015. U.S. Geological Survey National Produced Waters Geochemical Database v2.1 (PROVISIONAL),

CADOC, Monthly Production and Injection Databases 2011-2014, http://www.conservation.ca.gov/dog/prod_injection_db/Pages/Index.aspx.

Clark, C. E., and J. A. Veil 2009. Produced Water Volumes and Management Practices in the United StatesRep., Argonne Nationall Laboratory.

DrillingInfo, 2015. DrillingInfo Desktop Application, http://www.didesktop.com/.

Efron, Bradley, and R. J. Tibshirani 1994. An Introduction to the bootstrap, CRC press.

Ellsworth, W. L. 2013. Injection-Induced Earthquakes, Science, 341(6142), 142-+.

Elsarawy, A. M., H. A. Nasr-El-Din, and K. E. Cawiezel 2016. The effect of chelating agents on the use of produced water in crosslinked-gel-based hydraulic fracturing, paper presented at Society of Petroleum Engineers Low Pem Symposium Society of Petroleum Engineers, Denver Colorado, May 5, 2016.

Gallegos, T. J., B. A. Varela, S. S. Haines, and M. A. Engle 2015. Hydraulic fracturing water use variability in the United States and potential environmental implications, Water Resour. Res., 51(7).

Galusky, P., and T. D. Hayes 2011. Feasibility and Design Approach for Automated Classification and Segregation of Early Flowback Water for Reuse in Shale-Gas Hydraulic Fracturing.

Gregory, K. B., R. D. Vidic, and D. A. Dzombak 2011. Water Management Challenges Associated with the Production of Shale Gas by Hydraulic Fracturing, Elements, 7(3), 181-186.

Harkness, J., G. S. Dwyer, N. R. Warner, K. M. Parker, and W. A. Mitch 2015. Iodide, Bromide, and Ammonium in Hydraulic Fracturing and Oil and Gas Wastewaters; Environmental Implications, Environ. Sci. Technol., 49(3).

Hayes, T. 2009. Sampling and Analysis of Water Streams Associated with the Development of Marcellus Shale Gas..

Hurley, T., G. Chhipi-Shrestha, A. Gheisi, K. Hewage, and R. Sadiq 2016. Characterizing hydraulic fracturing fluid greenness: application of a hazard-based index approach, Clean Technol. Environ. Policy, 18, 647-668.

Ilk, D., J. A. Rushing, and A. D. Perego 2008. Exponential vs. Hyperbolic Decline in Tight Gas Sands Understanding the Origin and implications for Reserve Estimates Using Arps' Decline Curves, paper presented at Society of Petroleum Engineers Annual Technical Conference and Exhibition, Denver, CO.

Jackson, R. B., A. Vengosh, J. W. Carey, R. J. Davies, T. H. Darrah, F. O'Sullivan, and G. Petron 2014. The Environmental Costs and Benefits of Fracking, Annu. Rev. Environ. and Resour., 39, 327-367.

Kahrilas, G. A., J. Blotevogel, P. S. Stewart, and T. Borch 2015. Biocides in Hydraulic Fracturing Fluids: A Critical Review of Their Usage, Mobility, Degradation, and Toxicity, Environ. Sci. Technol., 49(1), 1632.

Kassotis, C. D., L. R. Iwanowicz, D. M. Akob, I. M. Cozzarelli, A. C. Mumford, W. H. Orem, and S. C. Nagel 2016. Endocrine disrupting activities of surface water associated with a West Virginia oil and gas industry wastewater disposal site, Sci. Total Environ., 557, 901-910.

Kondash, A., and A. Vengosh 2015. Water Footprint of Hydraulic Fracturing, Environ. Sci. Technol. Lett., 2(10), 276-280.

Kondash, A. J., N. R. Warner, O. Lahav, and A. Vengosh 2014. Radium and Barium Removal through Blending Hydraulic Fracturing Fluids with Acid Mine Drainage, Environ. Sci. Technol., 48(2), 1334-1342.

Lauer, N. E., J. S. Harkness, and A. Vengosh 2016. Brine Spills Associated with Unconventional Oil Development in North Dakota, Environ. Sci. Technol., 50(10), 5389-5397.

Lutz, B. D., A. N. Lewis, and M. W. Doyle 2013. Generation, transport, and disposal of wastewater associated with Marcellus Shale gas development, Water Resour. Res., 49, 647-656.

Mantell, M. E. 2011. Produced Water Reuse and Recycling Challenges and Opportunities Across Major Shale Plays, paper presented at EPA Hydraulic Fracturing Study Technical Workshop \#4 Water Resources Management, March 29-30. 
McLaughlin, M. C., T. Borch, and J. Blotevogel 2016. Spills of Hydraulic Fracturing Chemicals on Agricultrual Topsoil: Biodegradation, Sorption, and Co-contaminant Interactions, Environ. Sci. Technol., 50(11), 6071-6078.

Mohammad, J., J. Mohammad, and A. Siavash 2014. Reservoir Evaluation in Undersaturated Oil Reservoirs Using Modern Production Data Analysis; A Simulation Study, Science International, 26(3), 1089-1094.

Mohan, A. M., A. Hartsock, K. J. Bibby, R. W. Hammack, R. D. Vidic, and K. B. Gregory 2013. Microbial Community Changes in Hydraulic Fracturing Fluids and Produced Water from Shale Gas Extraction, Environ. Sci. Technol., 47(22), 13141-13150.

Murray, K. E. 2013. State-Scale Perspective on Water Use and Production Associated with Oil and Gas Operations, Oklahoma, U.S., Environ. Sci. Technol., 47, 4918-4925.

Mutalik, P. N., and S. D. Joshi 1992. Decline Curve Analysis Predicts Oil-Recovery from Horizontal Wells, Oil Gas J., 90(36), 42-48.

Nicot, J.-P., and B. R. Scanlon 2012. Water Use for Shale-Gas Production in Texas, U.S., Environ. Sci. Technol., 46, 3580-3586.

Nicot, J.-P., B. R. Scanlon, R. C. Reedy, and R. A. Costley 2014. Source and Fate of Hydraulic Fracturing Water in the Barnett Shale: A Historical Perspective, Environ. Sci. Technol., 48, 2464-2471.

Orem, W., C. Tatu, M. Varonka, H. Lerch, A. Bates, M. Engle, L. Crosby, and J. McIntosh 2014. Organic substances in produced and formation water from unconventional natural gas extraction in coal and shale, Int. J. Coal Geol., 126, 20-31.

PADEP, 2015. Oil and Gas Reporting - Electronic (OGRE) Public Reporting Data, www.paoilandgasreporting.state.pa.us/publicreports.

Rowan, E. L., M. A. Engle, T. F. Kraemer, K. T. Schroeder, R. W. Hammack, and M. W. Doughten 2015. Geochemical and isotopic evolution of water produced from Middle Devonian Marcellus shale gas wells, Appalachian basin, Pennsylvania, AAPG Bull., 99(2), 181-206.

Scanlon, B. R., R. C. Reedy, and J.-P. Nicot 2014a. Comparison of Water Use for Hydraulic Fracturing for Shale Oil and Gas versus Conventional Oil, Environ. Sci. Technol., 48, 12386-12393.

Scanlon, B. R., R. C. Reedy, and J.-P. Nicot 2014b. Will water scarcity in semiarid regions limit hydraulic fracturing of shale plays?, Environ. Res. Lett., 9.

Stepan, D. J., R. E. Shockey, B. A. Kurz, N. S. Kalenze, R. M. Cowan, J. J. Ziman, and J. A. Harju 2010. Bakken Water Opportunities Assessment - Phase 1., University of North Dakota.

Thacker, J. B., D. D. Carlton, Z. L. Hildenbrand, A. F. Kadjo, and K. A. Schug 2015. Chemical Analysis of Wastewater from Unconventional Drilling Operations, Water, 7(4), 1568-1579.

Thurman, E. M., I. Ferrer, J. Blotevogel, and T. Borch 2014. Analysis of Hydraulic Fracturing Flowback and Produced Waters Using Accurate Mass: Identification of Ethoxylated Surfactants, Anal. Chem., 86(19), 9653-9661.

Valko, P. P. 2009. Assigning Value to Stimulation in the Barnett Shale: A Simultaneous Analysis of 7000 Plus Production Histories and Well Completion Records, paper presented at SPE Hydraulic Fracturing Technology Conference, The Woodlands, TX.

Valko, P. P., and W. J. Lee 2010. A Better Way To Forecast Production From Unconventional Gas Wells, paper presented at Society of Petroleum Engineers Annual Technical Conference Florence, Italy.

Veil, J. A. 2010. Options for management of produced water, Geochim. Cosmochim. Acta, 74(12), A1078A1078.

Veil, J. A. 2015. Produced Water Volumes and Management Practices in 2012, Report prepared for the Groundwater Protection Council.

Veil, J. A., M. G. Puder, D. Elcock, and R. J. Redweik Jr. 2004. A White Paper Describing Produced Water from Production of Crude Oil, Natural Gas, and Coal Bed Methane.

Vengosh, A., R. B. Jackson, N. R. Warner, T. H. Darrah, and A. J. Kondash 2014a. A Critical Review of the Risks to Water Resources from Unconventional Shale Gas Development and Hydraulic Fracturing in the United States, Environ. Sci. Technol., 48(8334-8348).

Vengosh, A., R. B. Jackson, N. R. Warner, T. H. Darrah, and A. J. Kondash 2014b. A Critical Review of the Risks to Water Resources from Unconventional Shale Gas Development and Hydraulic Fracturing in the United States, Environ. Sci. Technol., 48(15), 8334-8348.

Wang, F., and S. Zhang 2014. Production Analysis of Multi-Stage Hydraulically Fractured Horizontal Wells in Tight Gas Reservoirs, Journal of Geography and Geology, 6(4), 58-67.

Warner, N. R., C. A. Christie, R. B. Jackson, and A. Vengosh 2013. Impacts of Shale Gas Wastewater Disposal on Water Quality in Western Pennsylvania, Environ. Sci. Technol., 47, 11849-11857. 
Warner, N. R., T. H. Darrah, R. B. Jackson, R. Millot, W. Kloppmann, and A. Vengosh 2014. New Tracers Identify Hydraulic Fracturing Fluids and Accidental Releases from Oil and Gas Operations, Environ. Sci. Technol., 48(21), 12552-12560.

Weingarten, M., S. Ge, J. W. Godt, B. A. Bekins, and J. L. Rubinsten 2015. High-rate injection is associated with the increase in U.S. mid-continent seismicity, Science, 348(6241), 1336-1340.

Wrobetz, A., and J. Gartner 2016. Wastewater Treatment Technologies in Natural Gas Hydraulic Fracturing: Executive SummaryRep., Navigant Research.

Yost, E. E., J. Stanek, R. S. DeWoskin, and L. D. Burgoon 2016a. Overview of Chronic Oral Toxicity Values for Chemicals Present in Hydraulic Fracturing Fluids, Flowback, and Produced Waters, Environ. Sci. Technol., 50(9), 4788-4797.

Yost, E. E., J. Stanek, R. S. DeWoskin, and L. D. Burgoon 2016b. Estimating the Potential Toxicity of Chemicals Associated with Hydraulic Fracturing Operations Using Quantitative Structure-Activity Relationship Modeling, Environ. Sci. Technol., Just Accepted Manuscript.

Yu, M. J., E. Weinthal, D. Patino-Echeverri, M. A. Deshusses, C. N. Zou, Y. Y. Ni, and A. Vengosh 2016. Water Availability for Shale Gas Development in Sichuan Basin, China, Environ. Sci. Technol., 50(6), 28372845. 